\title{
Experiments in political psychology
}

\section{Kyle Fischer ${ }^{1}$, Quentin D. Atkinson ${ }^{2}$, and Ananish Chaudhuri ${ }^{3}$}

This is a pre-print of a chapter that will appear in the forthcoming book, tentatively titled "A Research Agenda for Experimental Economics” edited by Ananish Chaudhuri, and has not yet been peer-reviewed.

$\begin{array}{ll}\text { Corresponding author: } & \text { Kyle Fischer } \\ & \text { Department of Psychology } \\ & \text { University of Auckland } \\ & \text { Science Centre 302 } \\ & \text { Level 3, Room 358 } \\ \text { 23 Symonds Street } & \text { Auckland 1010 } \\ \text { New Zealand } \\ \text { Phone: +64-9-923-4316 } \\ \text { E-mail: afis699@aucklanduni.ac.nz }\end{array}$

Acknowledgements: We thank the Royal Society New Zealand Marsden Fund for research support under Grant UOA-17-074. We are also grateful to Scott Claessens, Guy Lavender Forsyth, Chris Sibley, and Ryan GreenawayMcGrevy for feedback on the ideas contained in this chapter. 


\section{Introduction}

The political scientist Harold Lasswell famously described politics as the process of deciding "who gets what, when, and how". This suggests that the subject should be amenable to being studied with the aid of incentivised experiments where participants can earn real money based on the decisions they make. But, while commonplace in social psychology, the use of such experiments is still relatively rare in political psychology, with political psychologists largely relying on survey questions. While surveys can certainly be useful for understanding issues in political psychology, they also suffer from drawbacks. For example, surveys may not always reveal private preferences that participants would display in the absence of real-world social and cultural constraints (Pisor et al., 2020). In contrast, the presence of real monetary incentives in predominantly abstract and anonymous economic games can reveal true preferences such as the willingness to share. Consequently, behavioural economists tend to stress the value and importance of incentivised experiments (Chaudhuri, 2009; Smith, 1976, 1982).

Increasingly, researchers across a wide range of disciplines are turning toward experiments as a validated means of testing theoretical predictions. In this chapter, we will provide an overview of the use of incentivised experiments in political psychology, with an emphasis on the intertwined set of political beliefs, values, and attitudes that may be collectively referred to as political ideology. In doing so, we hope to facilitate a fruitful dialogue with researchers in political psychology, who may wish to explore the use of economic experiments (conceivably in conjunction with survey instruments) to study the basic dispositional antecedents of political ideology.

Traditionally, political scientists have tended to take a unidimensional view of political ideology, placing people along a liberal-conservative (left-right) spectrum. Liberals are generally egalitarian, more open to novelty, and supportive of redistributive policies, while conservatives are more concerned with preserving and enforcing traditional values, group conformity, and justifying existing hierarchies (Jost et al., 2003). However, scholars across diverse disciplines have repeatedly and independently found two primary dimensions of political ideology, often referred to as economic conservatism (vs. economic progressivism), and social conservatism (vs. social progressivism) (see Claessens et al., 2020a for details).

Recently, Claessens et al. (2020a) showed that there is a striking concordance between these dual dimensions of ideology and independent evidence for two key shifts in the evolution of human group living. First, humans began to cooperate more, and more widely. Second, humans became more group-minded, conforming to and enforcing social norms in culturally 
marked groups. They propose that fitness trade-offs and environmental pressures have maintained variation in these tendencies to cooperate and conform, naturally giving rise to the two dimensions of political ideology. We begin our overview by looking at experimental studies that take a unidimensional view of politics. We then discuss studies that use incentivised experiments to explore the dual foundations of political ideology. Finally, we conclude with some thoughts on future avenues of research.

\section{Experimental studies of unidimensional political ideology}

In this section, we provide an overview of experimental studies that adopt a unidimensional view of political ideology along a single left-right continuum. We split up our discussion into two subsections; one looking at pro-sociality, referring to cooperation, compassion, trust, reciprocity, altruism, and generosity in both individual and group contexts, and a second subsection that focuses on compliance with established norms and punishment of normviolators.

\subsection{Pro-sociality}

Anderson et al. (2005) recruited a small sample of undergraduates in the USA to play multiple rounds of trust and public goods games ${ }^{1}$, and found that Democrats or self-described liberals were no more pro-social than Republicans or self-described conservatives. Liberals were, however, more pro-social in the trust game when the experimenters induced inequality by giving some participants a higher endowment than others, suggesting that liberals' pro-sociality is connected to an aversion to inequality.

In another US study with a larger, more representative sample, there was no significant relationship between political ideology (self-described and measured with a Wilson-Patterson Inventory of Attitudes) and pro-sociality in the ultimatum game and a common pool resource extraction game (Alford \& Hibbing, 2007). Similarly, recent studies with relatively large samples have found no significant differences in pro-sociality between self-described leftleaning and right-leaning people in public goods games in Germany (Kistler et al., 2017), dictator games in the Netherlands (Thomsson \& Vostroknutov, 2017), and prisoner's dilemmas in the USA (Balliet et al., 2018). Moreover, Müller (2019) conducted a study using a dictator game and the "minimal group paradigm”, but found that neither self-described left- nor selfdescribed right-leaning people displayed ingroup-biased cooperation.

\footnotetext{
${ }^{1}$ We have provided a glossary in the Appendix describing all the games discussed in this chapter. Those not entirely familiar with these games may wish to consult the glossary before reading further.
} 
Interestingly, the Balliet et al. (2018) study referred to above also varied whether participants were playing with Democrats or Republicans in two-person prisoner's dilemmas, and found that both Democrats and Republicans displayed ingroup-biased cooperation mediated by trust that co-partisans would reciprocate. Other studies also found that partisans on both sides of the left-right spectrum, especially those who strongly identify with their party, gave more to co-partisans in the dictator game in the US, UK, Canada, and Sweden (Dawes et al., 2012; Fowler \& Kam, 2007), but this tendency was more pronounced among left-wing partisans (Dawes et al., 2012).

Given the political polarisation in the West, it is not surprising that both liberals and conservatives show ingroup bias in games where political groups are salient. What is less intuitive is that both liberals and conservatives who are more politically engaged/extreme/partisan (Dawes et al., 2011; Fehr et al., 2003; Fowler \& Kam, 2007; Müller \& Renes, 2019; Smirnov et al., 2010), tend to be more pro-social in standard games devoid of political content. This may be partly explained by the fact that the very act of engaging in political activities is a collective action problem and those who become so engaged on both sides are likely to be more pro-social to begin with.

However, a number of more recent studies including several based on large sample sizes provide evidence in favour of greater pro-social tendencies on the political left. Recent German studies found that: (1) left-leaning players in a modified dictator game were more prosocial (n = 116; Müller, 2019); (2) people in large, diverse samples on the political left (selfdescribed and determined by political party support) were more inclined to be egalitarian when playing as "third-party” allocators ( $=2,189$; Müller \& Renes, 2019), and (3) were likely to be characterised by benevolent traits like altruism and advantageous inequity-aversion (a dislike of having more than others) in two-person games whereas right-leaning people were likely to be characterised as "selfish”, “spiteful”, and “envious” ( $=2,794$; Kerschbamer \& Müller, 2020); (4) left-leaning people (self-described and measured by political party support) displayed more pro-social behaviour in public goods and trust games $(n=454$; Grünhage $\&$ Reuter, 2020). In addition, people who reported voting for the left-wing coalition government in Norway were more generous in dictator games (Cappelen et al., 2017). And in Denmark, Fosgaard et al. (2019) undertook a study with 1,926 participants and found that, in a public goods game, self-described left-leaning people contributed slightly (albeit not statistically significantly) more than self-described right-leaning people, but this difference reached statistical significance when the game was framed as taking from the public good. It is possible 
that the latter framing, which essentially turns the game into a common pool resource extraction game, elicits greater cooperation from left-leaning participants given their proclivity for being more environmentally conscious.

The greater pro-sociality of liberals is not limited to Europe. In an ambitious crosscountry study, Dawes et al. (2012) recruited over 5,000 participants from the US, UK, Canada, and Sweden to play a dictator game. Self-described left-leaning (vs. right-leaning) people were more generous in the US, UK, and Sweden (left-right ideology was not measured in Canada), and people who voted for left-wing (vs. right-wing) parties in Canada and Sweden were more generous. However, in the US, there were no differences between Democrats and Republicans, and in the UK, supporters of the left-wing Labour party were less generous than Tories and Liberal Democrats who tend to be more right-leaning.

Finally, studies conducted in the USA, Italy, and the Netherlands $(n=3,314)$ relying on the Social Values Orientation (SVO) measure of pro-sociality (involving non-incentivised decomposed prisoner's dilemmas) and measuring unidimensional political ideology with selfplacement, attitude scales, and/or party support, reveal that left-leaning people are more likely to be classified as pro-social while the right-leaning tend to be pro-self (Balliet et al., 2018; Chirumbolo et al., 2016; Sheldon \& Nichols, 2009; van Lange et al., 2012).

\subsection{Norm compliance and punishment of norm violators}

To our knowledge, only three studies have looked at the role of political ideology in terms of norm compliance and punishment of norm violations. In a recently developed computerised Rule Following Task, participants drag and drop balls into two buckets where every ball put in Bucket A yields say \$0.10 and every ball put in Bucket B yields half that amount. Participants are explicitly instructed that the rule is to put the balls in Bucket B. Therefore, the task measures willingness to pay a cost to follow an explicit rule, which is interpreted as social norm compliance (Kimbrough \& Vostroknutov, 2018). A study using the Rule Following Task found no difference between political liberals and conservatives in rule-following behaviour (Thomsson \& Vostroknutov, 2017). Interestingly, this study also investigated the norms that left- and right-leaning individuals held about giving in a dictator game, and found that while giving behaviour did not differ between left- and right-leaning people, their motives for giving did - right-leaning people seemed more concerned about their reputations as norm-followers in the eyes of the recipients.

Putterman et al. (2011) measured political attitudes of 80 undergraduates in the USA and examined whether, in a public goods game, they would vote for efficient centralised 
sanctioning schemes to punish free riding and encourage their groupmates to contribute. The authors report that political conservatives were less likely to vote for centralised punishments, a finding that may be related to the right's preference for greater self-reliance and smaller bureaucracies (at least in the US).

Using student participants $(n=120)$, Smirnov et al. (2010) examined whether partisans (those who explicitly identify as Democrat/Republican or strong Democrat/Republican) would display both cooperative and punitive behaviour in a public goods games and a random income game with the option of decentralised punishments. Both Republican and Democrat partisans were more likely than non-partisans to punish high-income players in the random income game and low-contributing players in the public goods game. That is, partisans on both sides of the left-right political spectrum seem inclined to engage in costly norm enforcement. One of the evolutionary functions of norm-enforcement is thought to be the facilitation of group cooperation and cohesion, especially during intergroup competition. Given the intense political polarisation prevalent in the West (i.e., the tribalism on, and competition between, the political left and right) it is not surprising that norm-enforcers are prevalent on both sides.

\subsection{Summary}

Taken together, the previous literature shows that political liberals tend to be more pro-social compared to political conservatives in economic games, but - going against the hypothesis that conservatives are more group-minded and conformist (Jost, 2017) - there tend to be no significant differences between liberals and conservatives in terms of ingroup-bias, normfollowing, and norm-enforcing behaviour (except one study showing that conservatives are less likely to vote for strict centralised sanctioning schemes). However, as we note above, this unidimensional view of political ideology is, if not incorrect, at least incomplete. We now turn to studies that explicitly acknowledge the two distinct dimensions of political ideology.

\section{Experimental studies of two-dimensional political ideology and related variables}

According to the Dual-Process Model of political ideology (Duckitt \& Sibley, 2009, 2017), economic conservatism - widely measured with the Social Dominance Orientation (SDO) scale - sees the world as a competitive jungle and reflects hierarchy-enhancing views. This economic dimension of ideology is associated (either positively or negatively) with constructs such as individualising (“care” and “fairness”) moral foundations (Nilsson \& Erlandsson, 2015; Federico et al., 2013), empathic concern and compassion (Chiao et al., 2009; Hirsh et al., 2010; Osborne et al., 2013), scores on Dark Triad scales (narcissism, Machiavellianism, and 
psychopathy; Jones \& Figueredo, 2013), HEXACO honesty-humility (Duckitt \& Sibley, 2017), justice sensitivity, i.e., inequality-aversion and social justice activism (Reese et al., 2014), and even physical formidability with physically stronger males more likely to be economic conservatives (Petersen \& Laustsen, 2019). For example, those who score higher on the SDO scale are typically less empathic and more comfortable with social hierarchies and economic inequality.

Social conservatism - often measured with the right-wing authoritarianism (RWA) scale - sees the world as a dangerous place and reflects conformity- and cohesion-enhancing views that aim to conserve and enforce existing group norms (e.g., religious family values). This social dimension of ideology is positively correlated with dispositional variables related to group-mindedness such as need for security, certainty, and conformity (Duckitt \& Sibley, 2009; Federico \& Malka, 2018), sensitivity to threats in the environment such as terrorism and pandemics (Shaffer \& Duckitt, 2013; Fischer et al., 2020a), as well as neurobiological variables related to threat-sensitivity like greater eyeblink startle response (Oxley et al., 2008).

Recently, Claessens et al., 2020a provided an evolutionary account of how these two dimensions of political ideology came about as a response to the essential challenges of human group living. These authors point out two key shifts in the evolution of human group living (Tomasello et al., 2012). The first of these required humans to cooperate more across wider interdependent networks and share the spoils of cooperation more evenly. This resulted in a human mind that was sensitive to the benefits of cooperative interactions with others and could extend cooperation beyond immediate genetic kin. But cooperation is a collective action problem that is vulnerable to free-riding from opportunists. And so, in a second key shift, as group sizes and intergroup competition increased, humans became more group-minded, conforming to social norms in culturally marked groups and punishing norm-violators, thereby facilitating group cohesion and long-term viability. Claessens et al., 2020a argue that behavioural plasticity and the fitness trade-offs between cooperation and self-interested competition, on the one hand, and between conformity and individualism on the other, maintain variation between individuals in human groups in terms of motivations to cooperate and conform. These individual differences in cooperativeness and conformity manifest in contemporary human populations as individual differences along the economic and social dimensions of political ideology, respectively.

Below, we review studies that focus on the dual foundations of political ideology by separately looking at the economic and social dimensions. Given that this is a new and 
emerging area of research, the literature here is not voluminous with lots of open research questions providing avenues for further studies. In many instances, researchers have undertaken studies that imply one or both of these dual dimensions without explicitly referring to them as such. We have tried to categorize these studies and results as systematically as possible using the dual foundations schema developed above.

\subsection{Experimental studies of economic conservatism/progressivism}

\subsubsection{Pro-sociality}

Little work has examined behaviour of people with economically conservative vs. economically progressive ${ }^{2}$ policy preferences, but there is some evidence that the latter tend to be more pro-social. Those who support increasing taxes to help the worse-off (an economically progressive position) display cooperative behaviour across a battery of games (Peysakhovich et al., 2014), and compared to economic conservatives, economic progressives are more prosocial in dictator games in the US and UK (Dawes et al., 2012), and two-person games in Germany (Kerschbamer \& Müller, 2020).

A number of studies look at the relation between economic conservatism/progressivism measured with the SDO scale and pro-sociality. In two studies with undergraduate students in Belgium, SDO was negatively correlated with pro-sociality in many, but not all, economic games (Haesevoets et al., 2015, 2018). In the first study, SDO was significantly negatively related to pro-sociality in dictator, commons dilemma, and one-shot public goods games, but was not in prisoner's dilemma, ultimatum, trust, stag hunt, and iterative public goods games. In the second study, SDO was negatively related to pro-sociality across different payoff structures in prisoner's dilemma games. The patterns across these studies were similar for RWA in that it negatively predicted pro-sociality in a subset of games.

One reason why SDO does not correlate with pro-sociality across all games could be that not all the games measure pro-sociality to the same extent, e.g., the dictator game is arguably a cleaner measure of pro-sociality while for social dilemmas, the notion of prosociality may be intermingled with other strategic considerations and beliefs about others'

\footnotetext{
${ }^{2}$ It may be useful to address the semantics involved. We refer to those who view the world as a competitive jungle and are more comfortable with hierarchy and inequality as "economic conservatives" and those who are in favour of greater equality, social justice, and redistributive economic policies as "economic progressives". In the literature, what we call "economic progressivism" is often called "economic liberalism" but we avoid using the latter because "economic liberalism” can also refer to support for free-market capitalism and opposition to the welfare state and other redistributive economic policies, all of which are actually economically conservative positions. Turning to the social dimension of ideology: "social conservatives" are those who favour adherence to established group norms, whereas "social progressives" (who can also be referred to as "social liberals") are those who are in favour of enhanced individual rights and liberties.
} 
actions. Another potential confound is that studies do not control for RWA (SDO) when exploring SDO’s (RWA's) relationship with pro-sociality. This is important because RWA and SDO are reliably correlated in the West and supress each other's effects on external variables (Costello \& Lilienfeld, 2020). Claessens et al., (2020b) accounted for this and recruited a much larger, representative sample $(\mathrm{n}=926)$ in New Zealand to examine whether SDO and RWA, controlling for demographic variables, differentially predicted cooperative and punitive latent variables (behavioural phenotypes) across a battery of economic games. They found that SDO (not RWA) significantly negatively predicted pro-sociality across the dictator, trust, ultimatum, public goods, stag hunt, and other games. Unlike Haesevoets et al. (2015, 2018), this shows that individual differences in a general cooperative phenotype, that applies across games with different payoff structures, predict individual differences in SDO, and not RWA.

Claessens et al., (2020b) also looked at Schwartz's values, which correspond to the two dimensions of political ideology with "self-enhancement” vs. "self-transcendence” values reflecting economic conservatism vs. economic progressivism, and “conservation” vs. “openness” values reflecting social conservatism vs. social progressivism. They found that, controlling for demographics, self-enhancement (self-transcendence) significantly negatively (positively) predicted the cooperative phenotype, while conservation and openness values were unrelated to this. Evidence from earlier work generally supports this, with self-enhancement values tending to be positively associated with selfish behaviour, self-transcendent values with pro-sociality, and conservation and openness values tending to be unrelated to pro-sociality in different games (Gärling, 1999; Sagiv et al., 2011).

A recent meta-analysis confirms that SDO is significantly negatively correlated with pro-social behaviour aggregated across a number of economic games (Thielmann et al., 2020). Moreover, variables positively associated with SDO, like the Dark Triad, competitiveness, and power, as well as negatively associated with SDO, such concern for others, inequity-aversion, agreeableness, honesty-humility, and empathy, are significantly related to pro-sociality. A recent German study not included in the meta-analysis above also shows that SDO mediated the relationship between left-right political affiliation and pro-social behaviour in a public goods game while, RWA mediated this relationship for a trust game (Grünhage \& Reuter, 2020). Moreover, studies using the SVO measure of pro-sociality show that SDO tends to be more strongly and consistently negatively correlated with pro-sociality than RWA is (Balliet et al., 2018; Chirumbolo et al., 2016; Haesevoets et al., 2015, 2018). 
Another noteworthy set of studies look at the connection between pro-sociality and environmentalism. Given that environmental problems like climate change represent social dilemmas - a conflict between self-interest and cooperation - we expect economic conservatives, compared to economic progressives, to be less willing to make sacrifices for the environment. Indeed, environmentalism is more strongly negatively associated with SDO than RWA (Häkkinen \& Akrami, 2014; Milfont et al., 2013, 2018; Stanley et al., 2019), and is positively associated with pro-social behaviour in economic games (Barclay \& Barker, 2020; Kaiser \& Byrka, 2011; Thielmann et al., 2020).

Finally, and in keeping with the concept of behavioural plasticity elucidated in the dual evolutionary foundations model of political ideology, pro-social behaviour is often influenced by situational cues. People low in honesty-humility, who tend to be high in SDO (Duckitt \& Sibley, 2017), cooperate more in public goods games when they face the possibility of punishment by their peers (Hilbig et al., 2012). Moreover, high-SDO individuals are particularly competitive and display increased greed, effort, and rule-breaking in situations of resource scarcity (Cozzolino \& Snyder, 2008). However, people in general tend to become more cooperative with resource abundance (Nettle et al., 2011) and when dominance hierarchies based on self-interest or effort/skill are removed or replaced with hierarchies based on altruism (Antonioni et al., 2018; Cronin et al., 2015), and this may apply to high-SDO individuals as well.

\subsubsection{Inequality}

A major facet of the economic dimension of political ideology is inequality-aversion, including redistributive preferences. Esarey et al. (2012) undertook a study where undergraduates could earn money by completing a multiple-choice spelling test, and then vote for different redistributive tax schemes. The money earned for the task was based on effort and skill (the task was difficult, tedious, performed under deadline pressure, and some people were better at it). There were also different conditions, a fair one (everyone got the same amount/penalty per correctly/incorrectly spelled word), one with inequality based on luck (subjects were randomly assigned to get a low or high pay rate), and one with inequality based on effort/skill in the task (after the first two periods, the top 50\% of spellers got a higher pay rate than the bottom 50\%). Results revealed that, regardless of condition, everyone tended to be self-interested, voting for higher taxes when they were poor, and lower taxes when they were rich, but economic conservatives tended to be more self-interested than economic progressives were. 
While the Esarey et al. (2012) study supports the view that economic conservatives tend to be more pro-self, it does not find differences between economic conservatives and economic progressives in terms of redistributive preferences. Since redistribution preferences are a defining feature of the economic dimension of ideology, future experiments should study this by varying aspects of the social situation (e.g., wealth can be based on effort, skill, or luck and redistribution can be based on equality or need). There is already suggestive evidence that such an approach will be fruitful. While Pratto et al. (1999) examined allocation decisions in hypothetical scenarios as opposed to economic games, they found that high-SDO individuals believe that fairness involves rewarding the meritorious and allocate more resources to meritorious parties, whereas low-SDO individuals believe that fairness involves helping the needy and allocate more resources to needy parties.

Furthermore, well-known correlates of economic progressivism such as social justice activism predict giving mostly to recipients from actual disadvantaged groups in modified dictator games (Fietzer et al., 2016). In third-party games where the participants witness one player financially harming another and can then help the victim or punish the perpetrator, justice sensitivity, empathic concern, compassion and the fairness moral foundation, are related to helping victims but not consistently related to punishing perpetrators (Baumert et al., 2014b; Weng et al., 2015; Leliveld et al., 2012; Zhao et al., 2017). However, varying the identities of perpetrators and victims may change this because, in general, people tend to punish perpetrators when the victims are evidently low status and the perpetrators, high status (Mattan et al., 2020).

Overall, existing evidence suggests that economic conservatives tend to be more proself but are happy with redistributing resources based on merit. In contrast, economic progressives may redistribute resources to help the disadvantaged and, to a lesser extent, punish the privileged.

\subsubsection{Within- and between-group competition}

SDO can be conceptualised as reflecting views that enhance both individual- and group-level hierarchy. On the individual level, this should manifest as self-interested competitiveness, and on the group level, it should manifest as a desire to dominate outgroups. In experimental studies, researchers have tried to tease out intergroup preferences by having participants choose between two or more of the following options in modified social dilemma games: (1) selfinterest, where the individual keeps their money and so does not make a personal sacrifice for their ingroup, (2) ingroup love, where the individual sacrifices money to benefit the ingroup but does not affect the outgroup, (3) outgroup hate, where the individual sacrifices money to 
benefit the ingroup and harm the outgroup, and (4) universalism, where the individual sacrifices money to benefit both ingroup and outgroup members (Aaldering \& Böhm, 2019; Fischer et al. 2020b; Halali et al., 2018). In such studies, group identity is either based on real groups (e.g., Jews vs. Palestinians) or manipulated via the minimal group paradigm (Tajfel \& Turner, 1979).

Taken together, the results suggest that SDO is positively related to self-interest and outgroup hate, unrelated to ingroup love, and negatively related to universalism (Aaldering \& Böhm, 2019; Fischer et al. 2020b; Halali et al., 2018). Along similar lines, a study measuring vertical individualism, a competitive, status-seeking type of individualism related to economic conservatism (Claessens et al., 2020a), finds that given a choice between self-interest and ingroup love, vertical individualists choose the former; but, given a choice between self-interest and outgroup hate, they choose the latter (Probst et al., 1999). Finally, Halevy et al. (2012) show that self-interest and outgroup hate increase perceptions of dominance, while universalism decreases this.

\subsection{Experimental studies of social conservatism/progressivism}

\subsubsection{Trust}

In Section 3.1.1., we found that economic rather than social conservatism is consistently negatively related to pro-sociality in general (Claessens et al., 2020b; Thielmann et al., 2020), but it seems that social conservatism is more consistently negatively related to one specific kind of pro-sociality: trusting strangers. Early research using the "Fascism" scale to measure authoritarianism found that it was significantly negatively correlated with trusting behaviour in a two-person non-zero-sum game (Deutsch, 1960). And more recently, many studies show that, compared to SDO, RWA is more reliably negatively related to trusting behaviour (Grünhage \& Reuter, 2020; Haesevoets et al., 2015; Ponsi et al., 2017, but see Claessens et al., 2020b). In fact, a meta-analysis showed that of all the widely used psychological variables (including trust propensity) other than SVO, RWA was the strongest correlate of distrustful behaviour in the trust game (Thielmann et al., 2020; supplemental materials).

Further evidence comes from studies looking at moral values. The mean of the binding moral foundations (ingroup loyalty, respect for authority, and purity), that are associated with social conservatism (Nilsson \& Erlandsson, 2015; Federico et al., 2013), significantly negatively correlates with behaviour in the trust game (Clark et al., 2017). Furthermore, secular values (non-traditional, non-religious), a proxy of social progressivism, in the World Values Survey are related to trusting (and efficient) behaviour in a property rights game (Kistler et al., 
2017). This is in line with work showing that religiosity (an important correlate of social conservatism) seems to be associated with less trust and is not consistently associated with other kinds of pro-sociality (e.g., Jacquet et al., 2020). E.g., a recent study found that religiosity is inversely related to trust in the trust game and not related to helping people in third-party games (Galen et al., 2020). This evidence suggests that social conservatives are relatively suspicious of anonymous strangers in economic games, which makes sense because social conservatism is conceptualised as parochial and fearful, reflecting trust only for ingroup members and wariness of outsiders (Claessens et al., 2020a).

\subsubsection{Norm following}

Fischer et al. (2020c) use the Rule Following Task developed by Kimbrough \& Vostroknutov (2018) to measure whether social conservatives are willing to forego monetary gains in order to comply with an explicit rule they have been told to follow (see Section 2.2 for details on the task). They find that measures of the social dimension of ideology, such as RWA, support for cultural tightness (Jackson et al., 2019), and security and conformity values (Schwartz et al., 2012), are related to rule-following behaviour (whereas SDO is only weakly negatively related to this).

Based on this result, indirect evidence on the social dimension of ideology can be garnered from how people who tend to follow rules in the Rule Following Task behave in subsequent public goods games. In one study (Gürdal, Torul, \& Vostroknutov, 2020), participants could choose between three groups with different rules (to put all, half, or any amount of their endowment into the common pool). Compared to rule-breakers, rule-followers tended to prefer groups with the strict rule to contribute the entire endowment and they followed the rules more (i.e., they cooperated more). In Kimbrough \& Vostroknutov (2016), participants were either sorted into groups based on their rule-following behaviour or placed into groups at random. Groups of rule-followers maintained higher levels of cooperation for longer periods compared to unsorted groups or groups of rule-breakers. However, in unsorted groups, individual rule-followers (compared to rule-breakers) did not tend to contribute more. Combined, these studies show that rule-followers prefer having strict rules in place, and when these rules state that they should cooperate at high levels, they do, and groups of rule-followers are particularly good at maintaining high levels of cooperation.

There is also some evidence that, like rule-followers, authoritarians contribute more in public goods games with strict, exogenously imposed contribution rules: In a study conducted in China - which is more collectivistic and accepting of authority and inequality 
compared to Western countries (Vollan et al., 2017) - 300 people including workers with a rural background and university students played public goods games in three conditions: (1) normal (2) authoritarian (with an exogenously imposed contribution rule to contribute the entire endowment), and (3) democratic (players could vote to implement the rule). In contrast to previous work in the West finding that democratically chosen rules work best at maintaining cooperation, the main result was that the exogenously imposed rule worked best and participants high in RWA cooperated most in this authoritarian condition; participants lower in RWA cooperated more in the democratic condition.

\subsubsection{Norm enforcement}

Yamagishi et al. (2012) and a recent meta-analysis (Thielmann et al., 2020) show that RWA and the personality trait openness, which is linked to social progressivism (Duckitt \& Sibley, 2017; Hirsh et al., 2010; Osborne et al., 2013), are related to punitive responses in the ultimatum game where participants are willing to forego money in order to punish another who is considered to be engaging in unfair behaviour. Moreover, Baumert et al. (2014b) found that the "authority" moral foundation (linked to social conservatism) was positively associated with punishment in the ultimatum game (but not in a third-party punishment game). And Chuah et al. (2009) report that valuing individual freedom (corresponding to social progressivism) was associated with less punitiveness in the ultimatum game while parochial attitudes (corresponding to social conservatism) were associated with more punitiveness.

Finally, threat-sensitivity is a well-known correlate of social conservatism and a recent study found that exposure to threat (violent crime) predicted punitive, not cooperative, behaviour across a battery of economic games (Littman et al., 2020). That is, threat coming from within the community seems to activate a norm-enforcing, punitive phenotype but not a cooperative one. However, Claessens et al. (2020b) did not find that RWA and conservation/openness values (that correspond to social conservatism/progressivism) generally predict a norm-enforcing, punitive phenotype.

The evidence we have covered here broadly supports the view that, compared to the economic dimension of ideology, the social dimension is more consistently related to punitiveness, at least in the ultimatum game. The reason social conservatism and related variables are often associated with punitive behaviour in the ultimatum game may be that 
punitiveness in this game seems to reflect normative rather than pro-social or anti-social behaviour (Brañas-Garza et al., 2014; Brethel-Haurwitz et al., 2016; Yamagishi et al., 2012). ${ }^{3}$

\subsubsection{Ingroup bias}

Given that social conservatives are theoretically ingroup-focussed and wary of cooperating with anonymous strangers, they should only cooperate with trusted ingroup members with whom they feel interdependent, and not with outgroup members in intergroup economic games. Those games (mentioned in Section 3.1.3) that ask participants to choose from self-interest, ingroup love, outgroup hate, and universalism, allow us to study the relationship between group-mindedness and social conservatism. Recently, Fischer et al. (2020b) found that rightwing authoritarians tended to engage in ingroup love (including identifying with the artificial ingroup) and outgroup hate - RWA was unrelated to self-interest and universalism. An older study (also mentioned in Section 3.1.3) looked at the behaviour in single-group (measuring self-interest vs. ingroup love) and intergroup (measuring self-interest vs. outgroup hate) prisoner's dilemmas and found that vertical collectivists, similar to social conservatives (see Claessens et al., 2020a), were inclined to choose ingroup love and disinclined to choose outgroup hate (Probst et al., 1999).

\section{Conclusion}

Overall, studies on unidimensional political ideology using economic games paint conservatives as less pro-social than liberals. However, many studies also show that there are no large differences between liberals and conservatives in pro-sociality (especially ingroupfocussed pro-sociality) as well as norm compliance, and punitive behaviour. We argue that the likely explanation for this is that unidimensional measures of ideology are too crude to reveal underlying behavioural differences between people with different ideologies.

Indeed, studies that examine the two primary dimensions of ideology reveal important differences. The evidence on the economic dimension of ideology clearly points to an underlying behavioural phenotype characterised by competition vs. cooperation. That is, economic conservatism seems to be underpinned by a predisposition for within-group competition (self-interest, sometimes manifesting as punishment to gain an advantage over

\footnotetext{
${ }^{3}$ In contrast, the reason economic conservatism (Claessens et al., 2020b) and its correlates like self-reported dominance (Pfattheicher et al., 2014) and disagreeableness (Roberts et al., 2013) are sometimes related to punitiveness in games other than the ultimatum game, may be that punitive behaviour in these games is often driven by self-interest, spite, competitiveness, and power (Hilbe \& Traulsen, 2012; Houser \& Xiao, 2010; Raihani \& Bshary, 2019). This is the case for prisoner's dilemma (Falk et al., 2005), third-party (Delton \& Krasnow, 2017; Leliveld et al., 2012), and public goods games (Herrmann et al., 2008; Hoeft \& Mill, 2017; Krasnow et al., 2012; Pfattheicher et al., 2014), and even for the punishment phenotype found across games (Chierchia et al., 2017).
} 
others) and between-group competition (outgroup hate). In contrast, economic progressivism seems to be underpinned by cooperation extending beyond group boundaries (universalism) and compassion for the disadvantaged. Less research has been conducted on the social dimension of ideology, but social conservatism seems to be characterised by a drive to maintain group conformity. In economic games, social conservatives distrust anonymous strangers, follow rules/norms, punish more (at least in some games), and display both ingroup love and outgroup hate. These results are consistent with the fact that people high in SDO view the world as a competitive jungle or zero-sum game whereas people high in RWA view the world as dangerous and uncertain and therefore turn inwards to their groups for protection and lash out at threatening outgroups.

Findings based on the dual dimensions of ideology also help to explain results from unidimensional studies. They suggest that the pro-sociality associated with liberalism is driven by economic, rather than, social progressivism. Moreover, when unidimensional measures of ideology are used, the social dimension of ideology may mask the effect of the economic dimension on pro-sociality, which would explain why many studies fail to find greater prosociality among those classified as liberal on unidimensional measures. Moreover, experiments on the dual dimensions suggest that the negative relationship between unidimensional conservatism and trust is driven by social conservatism. And the similar levels of ingroupbiased, normative, and punitive behaviour on both ends of the unidimensional spectrum may be driven by left- and right-wing authoritarians, but this requires further research.

We hope this chapter has laid the foundation for a fruitful dialogue between political science and behavioural economics. The studies reviewed here and the gaps identified should provide ample opportunities for future cross-disciplinary collaboration. As we have seen, incentivised experiments are a valuable tool for uncovering basic dispositional differences and similarities between people with different ideologies. This can foster more understanding across political divides and help experts and laypeople alike to gain a firmer grasp of what fuels our political behaviour. 


\section{Appendix: Glossary of Games}

Below, we provide a description of some behavioural economic games commonly deployed to investigate social preferences related to ideology. All dollar amounts are just examples to help illustrate the structure of the game and approximate relative size of incentives.

\section{Dictator Game}

This is a sequential two-player game. The first mover has $\$ 10$; the second mover has no initial endowment. The first mover decides how much of this $\$ 10$ to send to the second mover. The second mover has no decision to make. The amount sent by first mover is considered a measure of the first mover's level of generosity/altruism.

\section{Ultimatum Game}

This is a sequential two-player game. The first mover has $\$ 10$; the second mover has no initial endowment. The first mover decides on a split of the initial endowment of \$10 (say \$7 and \$3). This decision is then conveyed to the second mover who can either accept or reject offer. If the second mover accepts then each gets the split offered by the first mover (first mover gets $\$ 7$, second mover gets \$3). But, if the second mover rejects, then both get nothing. This game (and the second mover's decision to reject small offers) is often used to measure preferences regarding fairness.

\section{Trust Game}

This is a sequential two-player game. Typically, both players start with an initial endowment of $\$ 10$. The first mover can choose to send any or all of $\$ 10$ to the second mover. Any amount (\$X) sent is multiplied typically by 3 and this tripled amount $(\$ 3 X)$ is given to the second mover. (If the amount is doubled/quadrupled then second mover gets $2 \mathrm{X} / 4 \mathrm{X}$ etc.) The second mover then decides whether to send anything back to the first mover. The latter amount is not multiplied. The amount sent by the first mover is considered a measure of "trust" while the proportion returned by the second mover is considered a measure of trustworthiness/reciprocity. (Since different second movers get different amounts, one cannot look at the absolute amount returned by the second mover but rather the proportion returned.) 


\section{Public Goods Game}

This is a group decision-making game, typically with more than two players such as four, five or more. Let us say a group consists of five players. Each player has \$5 and can keep this entire amount or contribute any or all to the public (group) account. Decisions are made simultaneously. The amount put in the public account is multiplied by $M$. This can be any number higher than one but less than the number of players such that M/5 is less than 1; i.e., the multiplied amount divided by the number of players is less than 1. So if there are five players then $M$ could be 2, 3, or 4 (implying that the marginal per capita return $=\$ 0.4$, $\$ 0.6$, or $\$ 0.8$ respectively). This makes it a dominant strategy to free-ride by keeping the entire $\$ 5$ in one’s private account. The social optimum is for every player to contribute everything to the public account as this generates the highest returns for every player.

\section{Prisoner's Dilemma Game}

\begin{tabular}{|l|c|c|c|}
\hline \multirow{2}{*}{ Player \#1 } & \multicolumn{3}{|c|}{ Player \#2 } \\
\cline { 2 - 4 } & & Cooperate & Defect \\
\cline { 2 - 4 } & Cooperate & $\$ 3, \$ 3$ & $\$ 0, \$ 4$ \\
\cline { 2 - 4 } & Defect & $\$ 4, \$ 0$ & $\$ 1, \$ 1$ \\
\hline
\end{tabular}

This is a paired game with decisions made simultaneously. Each player can choose from one of two strategies, generically referred to as "Cooperate” or "Defect”. If both players choose “Cooperate” then they each get $\$ 3$. If they both choose “Defect” then each gets $\$ 1$. If one player chooses "Cooperate" while the other chooses "Defect" then the player choosing to cooperate gets $\$ 0$ while the defecting player gets $\$ 4$. Defect is the dominant strategy for both players resulting in a unique dominant strategy Nash equilibrium of $\{$ Defect, Defect $\}$, where each gets $\$ 1$; even though \{Cooperate, Cooperate is socially optimal and maximizes payoff for both players with each getting $\$ 3$. This is because regardless of what the other player chooses ("Cooperate” or "Defect”), the other player is better off choosing "Defect”. For each player “Defect” yields \$4 as opposed to \$3 (from “Cooperate”) if the other player chooses to “Cooperate”. And "Defect” yields \$1 as opposed to \$0 (from “Cooperate”) if the other player chooses "Defect” also. 


\section{Payoff Ranked Coordination (Stag Hunt) Game}

\begin{tabular}{|l|c|c|c|}
\hline \multirow{2}{*}{ Player \#1 } & \multicolumn{3}{|c|}{ Player \#2 } \\
\cline { 2 - 4 } & & Hunt Stag & Hunt Rabbit \\
\cline { 2 - 4 } & Hunt Stag & $\$ 8, \$ 8$ & $\$ 0, \$ 5$ \\
\cline { 2 - 4 } & Hunt Rabbit & $\$ 5, \$ 0$ & $\$ 5, \$ 5$ \\
\hline
\end{tabular}

This is a paired game with decisions made simultaneously. Each player can choose from one of two strategies: hunt stag or hunt rabbit. If both players choose "hunt stag" then they both get $\$ 8$ each. If they both choose "hunt rabbit" then they both get \$5 each. If one player chooses "hunt stag” while the other chooses "hunt rabbit" then the player choosing "hunt stag” gets \$0 while the player choosing "hunt rabbit” gets $\$ 5$. This game has two Nash equilibria: one where both players choose to hunt stag and a second where both players choose to hunt rabbit. The former is the payoff dominant equilibrium in the sense that both players gets a higher payoff of $\$ 8$ each at this equilibrium. The latter is the secure (or risk dominant) equilibrium. This is because a player can guarantee a payoff of $\$ 5$ for themselves by choosing “hunt rabbit” (yields \$5 regardless of what the other player chooses).

\section{Second-Party Punishment Game}

There are two players, each with $\$ 10$. This game has two stages: the transfer stage, and the penalty stage. In the transfer stage, each player decides whether to transfer $\$ 3$ to the other player. Any amount transferred is doubled and given to the other player. Decisions are made simultaneously. Players get to see the outcome of transfer stage. Next, there is a penalty stage with decisions made simultaneously again. Both players can pay up to $\$ 1$ to reduce the other player's payoff, depending on the decisions made in the transfer stage. $\$ 1$ given by one player reduces the other player's payoff by $\$ 5$.

\section{Third-Party Punishment Game}

Three players, A, B, and C all start with \$10. First, Player A decides whether to 'take' from Player B. If Player A takes, Player B loses \$5 points and Player A gains \$3 points (taking is inefficient). If Player A takes, Player C can then pay up to $\$ 2$ to reduce Player A's payoff. Each $\$ 1$ given by Player C reduces $\$ 5$ from Player A. Player B is passive in the interaction. 


\section{Random Income Game}

In the random income game, participants are put into groups of four and given a random endowment that their peers could see. Players could then pay a cost to take money away from or give money to their groupmates. Decisions are made simultaneously.

\section{References:}

Aaldering, H., \& Böhm, R. (2020). Parochial versus universal cooperation: introducing a novel economic game of within-and between-group interaction. Social Psychological and Personality Science, 11(1), 36-45.

Alford, J. R., \& Hibbing, J. R. (2007). Personal, interpersonal, and political temperaments. The Annals of the American Academy of Political and Social Science, 614(1), 196-212.

Anderson, L. R., Milyo, J., \& Mellor, J. M. (2004). Do liberals play nice? The effects of party and political ideology in public goods and trust games. In J. Morgan (Ed.), Experimental and Behavorial Economics (Advances in Applied Microeconomics, Vol. 13) (pp. 97-106). Emerald Group Publishing Limited, Bingley.

Antonioni, A., Pereda, M., Cronin, K. A., Tomassini, M., \& Sánchez, A. (2018). Collaborative hierarchy maintains cooperation in asymmetric games. Scientific Reports, 8(1), 1-9.

Balliet, D., Tybur, J. M., Wu, J., Antonellis, C., \& Van Lange, P. A. (2018). Political ideology, trust, and cooperation: in-group favoritism among Republicans and Democrats during a US national election. Journal of Conflict Resolution, 62(4), 797-818.

Barclay, P., \& Barker, J. L. (2020). Greener than thou: people who protect the environment are more cooperative, compete to be environmental, and benefit from reputation. Journal of Environmental Psychology, 101441.

Baumert, A., Beierlein, C., Schmitt, M., Kemper, C. J., Kovaleva, A., Liebig, S., \& Rammstedt, B. (2014). Measuring four perspectives of justice sensitivity with two items each. Journal of Personality Assessment, 96(3), 380-390.

Baumert, A., Schlösser, T., \& Schmitt, M. (2014). Economic games: a performance-based assessment of fairness and altruism. European Journal of Psychological Assessment, 30(3), 178-192.

Brañas-Garza, P., Espín, A. M., Exadaktylos, F., \& Herrmann, B. (2014). Fair and unfair punishers coexist in the Ultimatum Game. Scientific Reports, 4(1), 1-4.

Brethel-Haurwitz, K. M., Stoycos, S. A., Cardinale, E. M., Huebner, B., \& Marsh, A. A. (2016). Is costly punishment altruistic? Exploring rejection of unfair offers in the Ultimatum Game in real-world altruists. Scientific Reports, 6(1), 1-10.

Cappelen, A. W., Halvorsen, T., Sørensen, E. Ø., \& Tungodden, B. (2017). Face-saving or fairminded: what motivates moral behavior?. Journal of the European Economic Association, 15(3), 540-557.

Chaudhuri, A. (2009). Experiments in Economics: Playing Fair with Money. London and New York: Routledge.

Chiao, J., Mathur, V., Harada, T., \& Lipke, T. (2009). Neural basis of preference for human social hierarchy versus egalitarianism. Annals of the New York Academy of Sciences, 1167(1), 174-181.

Chierchia, G., Lesemann, F. P., Snower, D., Vogel, M., \& Singer, T. (2017). Caring cooperators and powerful punishers: differential effects of induced care and power motivation on different types of economic decision making. Scientific Reports, 7(1), 1-10. 
Chirumbolo, A., Leone, L., \& Desimoni, M. (2016). The interpersonal roots of politics: Social value orientation, socio-political attitudes and prejudice. Personality and Individual Differences, 91, 144-153.

Chuah, S. H., Hoffmann, R., Jones, M., \& Williams, G. (2009). An economic anatomy of culture: attitudes and behaviour in inter- and intra-national ultimatum game experiments. Journal of Economic Psychology, 30(5), 732-744.

Claessens, S., Fischer, K., Chaudhuri, A., Sibley, C. G., \& Atkinson, Q. D. (2020a). The dual evolutionary foundations of political ideology. Nature Human Behaviour, 1-10.

Claessens, S., Sibley, C., Chaudhuri, A., \& Atkinson, Q. D. (2020b). Cooperative phenotype predicts economic conservatism, policy views, and political party support [Preprint].

Clark, C. B., Swails, J. A., Pontinen, H. M., Bowerman, S. E., Kriz, K. A., \& Hendricks, P. S. (2017). A behavioral economic assessment of individualizing versus binding moral foundations. Personality and Individual Differences, 112, 49-54.

Costello, T. H., \& Lilienfeld, S. O. (2020). Social and economic political ideology consistently operate as mutual suppressors: implications for personality, social, and political psychology [Preprint].

Cozzolino, P. J., \& Snyder, M. (2008). Good times, bad times: How personal disadvantage moderates the relationship between social dominance and efforts to win. Personality and Social Psychology Bulletin, 34(10), 1420-1433.

Cronin, K. A., Acheson, D. J., Hernández, P., \& Sánchez, A. (2015). Hierarchy is detrimental for human cooperation. Scientific Reports, 5, 18634.

Dawes, C. T., Johannesson, M., Lindqvist, E., Loewen, P. J., Ostling, R., Bonde, M., \& Priks, F. (2012). Generosity and political preferences. SSRN Electronic Journal, 941.

Dawes, C. T., Loewen, P. J., \& Fowler, J. H. (2011). Social preferences and political participation. The Journal of Politics, 73(3), 845-856.

Delton, A. W., \& Krasnow, M. M. (2017). The psychology of deterrence explains why group membership matters for third-party punishment. Evolution and Human Behavior, 38(6), 734-743.

Deutsch, M. (1960). Trust, trustworthiness, and the F Scale. The Journal of Abnormal and Social Psychology, 61(1), 138.

Duckitt, J., \& Sibley, C. G. (2009). A dual-process motivational model of ideology, politics, and prejudice. Psychological Inquiry, 20(2-3), 98-109.

Duckitt, J., \& Sibley, C. G. (2017). The dual process motivational model of ideology and prejudice. In C. G. Sibley \& F. K. Barlow (Eds.), The Cambridge Handbook Of The Psychology Of Prejudice (pp. 188-221). Cambridge: Cambridge University Press.

Esarey, J., Salmon, T. C., \& Barrilleaux, C. (2012). What motivates political preferences? Selfinterest, ideology, and fairness in a laboratory democracy. Economic Inquiry, 50(3), 604624.

Falk, A., Fehr, E., \& Fischbacher, U. (2005). Driving forces behind informal sanctions. Econometrica, 73(6), 2017-2030.

Federico, C. M., Weber, C. R., Ergun, D., \& Hunt, C. (2013). Mapping the connections between politics and morality: the multiple sociopolitical orientations involved in moral intuition. Political Psychology, 34(4), 589-610.

Federico, C. M., \& Malka, A. (2018). The contingent, contextual nature of the relationship between needs for security and certainty and political preferences: Evidence and implications. Political Psychology, 39, 3-48.

Fehr, E., Fischbacher, U., Von Rosenbladt, B., Schupp, J., \& Wagner, G. G. (2003). A nationwide laboratory: examining trust and trustworthiness by integrating behavioral experiments into representative survey. IZA Discussion Paper No. 715, Bonn, Germany 
Fietzer, A. W., Ponterotto, J. G., Jackson, M. A., \& Bolgatz, J. (2016). Cultural adjustment and social justice behaviour: The role of individual differences in multicultural personality. European Journal of Personality, 30(6), 552-563.

Fischer, K., Chaudhuri, A., \& Atkinson, Q. D. (2020a). The dual evolutionary foundations of political ideology predict responses to the COVID-19 pandemic [working paper].

Fischer, K., Chaudhuri, A., Sibley, C., \& Atkinson, Q. D. (2020b). The dual evolutionary foundations of political ideology differentially predict egoism, ingroup love, outgroup hate, and universalism [working paper].

Fischer, K., Claessens, S., Tremewan, J., Fišar, M., Špalek, J., Chaudhuri, A., Sibley, C., \& Atkinson, Q. D. (2020c). Right- and left-wing authoritarianism predict measures of conformity and threat/disgust sensitivity [working paper].

Fosgaard, T. R., Hansen, L. G., \& Wengström, E. (2019). Cooperation, framing, and political attitudes. Journal of Economic Behavior \& Organization, 158, 416-427.

Fowler, J. H., \& Kam, C. D. (2007). Beyond the self: social identity, altruism, and political participation. The Journal of Politics, 69(3), 813-827.

Galen, L. W., Kurby, C. A., \& Fles, E. H. (2020). Religiosity, shared identity, trust, and punishment of norm violations: no evidence of generalized prosociality. Psychology of Religion and Spirituality. Advance online publication.

Gärling, T. (1999). Value priorities, social value orientations and cooperation in social dilemmas. British Journal of Social Psychology, 38(4), 397-408.

Grünhage, T., \& Reuter, M. (2020). Political orientation is associated with behavior in publicgoods- and trust-games. Political Behavior, 1-26.

Gürdal, M. Y., Torul, O., \& Vostroknutov, A. (2020). Norm compliance, enforcement, and the survival of redistributive institutions. Journal of Economic Behavior \& Organization, 178, 313-326.

Haesevoets, T., Folmer, C. R., \& Van Hiel, A. (2015). Cooperation in mixed-motive games: the role of individual differences in selfish and social orientation. European Journal of Personality, 29(4), 445-458.

Haesevoets, T., Reinders Folmer, C., Bostyn, D. H., \& Van Hiel, A. (2018). Behavioural consistency within the prisoner's dilemma game: the role of personality and situation. European Journal of Personality, 32(4), 405-426.

Häkkinen, K., \& Akrami, N. (2014). Ideology and climate change denial. Personality and Individual Differences, 70, 62-65.

Halali, E., Dorfman, A., Jun, S., \& Halevy, N. (2018). More for us or more for me? Social dominance as parochial egoism. Social Psychological and Personality Science, 9(2), 254262.

Halevy, N., Chou, E. Y., Cohen, T. R., \& Livingston, R. W. (2012). Status conferral in intergroup social dilemmas: behavioral antecedents and consequences of prestige and dominance. Journal of Personality and Social Psychology, 102(2), 351.

Herrmann, B., Thöni, C., \& Gächter, S. (2008). Antisocial punishment across societies. Science, 319(5868), 1362-1367.

Hilbe, C., \& Traulsen, A. (2012). Emergence of responsible sanctions without second order free riders, antisocial punishment or spite. Scientific Reports, 2, 458.

Hilbig, B. E., Zettler, I., \& Heydasch, T. (2012). Personality, punishment and public goods: strategic shifts towards cooperation as a matter of dispositional honesty-humility. European Journal of Personality, 26(3), 245-254.

Hirsh, J. B., DeYoung, C. G., Xu, X., \& Peterson, J. B. (2010). Compassionate liberals and polite conservatives: associations of agreeableness with political ideology and moral values. Personality and Social Psychology Bulletin, 36(5), 655-664. 
Hoeft, L., \& Mill, W. (2017). Selfish punishers: an experimental investigation of designated punishment behavior in public goods. Economics Letters, 157, 41-44.

Houser, D., \& Xiao, E. (2010). Inequality-seeking punishment. Economics Letters, 109(1), 2023.

Jacquet, P. O., Pazhoohi, F., Findling, C., Mell, H., Chevallier, C., \& Baumard, N. (2020). Predictive multivariate modelling of religiosity in 295000 individuals from WEIRD and non-WEIRD populations [Preprint].

Jones, D. N., \& Figueredo, A. J. (2013). The core of darkness: uncovering the heart of the Dark Triad. European Journal of Personality, 27(6), 521-531.

Jost, J. T. (2017). Ideological asymmetries and the essence of political psychology. Political Psychology, 38(2), 167-208.

Jost, J. T., Glaser, J., Kruglanski, A. W., \& Sulloway, F. J. (2003). Political conservatism as motivated social cognition. Psychological Bulletin, 129(3), 339.

Kaiser, F. G., \& Byrka, K. (2011). Environmentalism as a trait: gauging people's prosocial personality in terms of environmental engagement. International Journal of Psychology, 46(1), 71-79.

Kerschbamer, R., \& Müller, D. (2020). Social preferences and political attitudes: an online experiment on a large heterogeneous sample. Journal of Public Economics, 182, 104076.

Kimbrough, E. O., \& Vostroknutov, A. (2018). A portable method of eliciting respect for social norms. Economics Letters, 168, 147-150.

Kimbrough, E. O., \& Vostroknutov, A. (2016). Norms make preferences social. Journal of the European Economic Association, 14(3), 608-638.

Kistler, D., Thöni, C., \& Welzel, C. (2017). Survey response and observed behavior: emancipative and secular values predict prosocial behaviors. Journal of Cross-Cultural Psychology, 48(4), 461-489.

Krasnow, M. M., Cosmides, L., Pedersen, E. J., \& Tooby, J. (2012). What are punishment and reputation for?. PLoS One, 7(9), e45662.

Leliveld, M. C., van Dijk, E., \& van Beest, I. (2012). Punishing and compensating others at your own expense: the role of empathic concern on reactions to distributive injustice. European Journal of Social Psychology, 42(2), 135-140.

Littman, R., Estrada, S., Stagnaro, M. N., Dunham, Y., Rand, D., \& Baskin-Sommers, A. (2020). Community violence and prosociality: experiencing and committing violence predicts norm-enforcing punishment but not cooperation. Social Psychological and Personality Science, 11(2), 276-283.

Mattan, B. D., Barth, D. M., Thompson, A., FeldmanHall, O., Cloutier, J., \& Kubota, J. T. (2020). Punishing the privileged: selfish offers from high-status allocators elicit greater punishment from third-party arbitrators. PloS one, 15(5), e0232369.

Milfont, T. L., Bain, P. G., Kashima, Y., Corral-Verdugo, V., Pasquali, C., Johansson, L. O., ... \& Bilewicz, M. (2018). On the relation between social dominance orientation and environmentalism: a 25-nation study. Social Psychological and Personality Science, 9(7), 802-814.

Milfont, T. L., Richter, I., Sibley, C. G., Wilson, M. S., \& Fischer, R. (2013). Environmental consequences of the desire to dominate and be superior. Personality and Social Psychology Bulletin, 39(9), 1127-1138.

Müller, D. (2019). The anatomy of distributional preferences with group identity. Journal of Economic Behavior \& Organization, 166, 785-807.

Müller, D., \& Renes, S. (2019). Fairness views and political preferences: evidence from a representative sample (No. 2019-08). Working Papers in Economics and Statistics. 
Nettle, D., Colléony, A., \& Cockerill, M. (2011). Variation in cooperative behaviour within a single city. PloS One, 6(10).

Nilsson, A., \& Erlandsson, A. (2015). The Moral Foundations taxonomy: structural validity and relation to political ideology in Sweden. Personality and Individual Differences, 76, 2832.

Osborne, D., Wootton, L. W., \& Sibley, C. G. (2013). Are liberals agreeable or not?. Social Psychology, 44, 354-360.

Oxley, D. R., Smith, K. B., Alford, J. R., Hibbing, M. V., Miller, J. L., Scalora, M., ... \& Hibbing, J. R. (2008). Political attitudes vary with physiological traits. Science, 321(5896), 1667-1670.

Petersen, M. B., \& Laustsen, L. (2019). Upper-body strength and political egalitarianism: twelve conceptual replications. Political Psychology, 40(2), 375-394.

Pfattheicher, S., Landhäußer, A., \& Keller, J. (2014). Individual differences in antisocial punishment in public goods situations: the interplay of cortisol with testosterone and dominance. Journal of Behavioral Decision Making, 27(4), 340-348.

Pisor, A. C., Gervais, M. M., Purzycki, B. G., \& Ross, C. T. (2020). Preferences and constraints: the value of economic games for studying human behaviour. Royal Society Open Science, 7(6), 192090.

Ponsi, G., Panasiti, M. S., Aglioti, S. M., \& Liuzza, M. T. (2017). Right-wing authoritarianism and stereotype-driven expectations interact in shaping intergroup trust in one-shot vs multiple-round social interactions. PloS One, 12(12), e0190142.

Pratto, F., Tatar, D. G., \& Conway-Lanz, S. (1999). Who gets what and why: determinants of social allocations. Political Psychology, 20(1), 127-150.

Probst, T. M., Carnevale, P. J., \& Triandis, H. C. (1999). Cultural values in intergroup and single-group social dilemmas. Organizational Behavior and Human Decision Processes, 77(3), 171-191.

Putterman, L., Tyran, J. R., \& Kamei, K. (2011). Public goods and voting on formal sanction schemes. Journal of Public Economics, 95(9-10), 1213-1222.

Peysakhovich, A., Nowak, M. A., \& Rand, D. G. (2014). Humans display a 'cooperative phenotype' that is domain general and temporally stable. Nature Communications, 5(1), 18.

Raihani, N. J., \& Bshary, R. (2019). Punishment: one tool, many uses. Evolutionary Human Sciences, 1.

Reese, G., Proch, J., \& Cohrs, J. C. (2014). Individual differences in responses to global inequality. Analyses of Social Issues and Public Policy, 14(1), 217-238.

Roberts, S. C., Vakirtzis, A., Kristjánsdóttir, L., \& Havlíček, J. (2013). Who punishes? Personality traits predict individual variation in punitive sentiment. Evolutionary Psychology, 11(1), 147470491301100117.

Sagiv, L., Sverdlik, N., \& Schwarz, N. (2011). To compete or to cooperate? Values' impact on perception and action in social dilemma games. European Journal of Social Psychology, 41(1), 64-77.

Schwartz, S. H., Cieciuch, J., Vecchione, M., Davidov, E., Fischer, R., Beierlein, C., ... \& Dirilen-Gumus, O. (2012). Refining the theory of basic individual values. Journal of Personality and Social Psychology, 103(4), 663.

Shaffer, B., \& Duckitt, J. (2013). The dimensional structure of people's fears, threats, and concerns and their relationship with right-wing authoritarianism and social dominance orientation. International Journal of Psychology, 48(1), 6-17.

Sheldon, K. M., \& Nichols, C. P. (2009). Comparing Democrats and Republicans on intrinsic and extrinsic values. Journal of Applied Social Psychology, 39(3), 589-623. 
Sidanius, J., Liu, J. H., Shaw, J. S., \& Pratto, F. (1994). Social dominance orientation, hierarchy attenuators and hierarchy enhancers: Social dominance theory and the criminal justice system. Journal of Applied Social Psychology, 24(4), 338-366.

Sidanius, J., Pratto, F., \& Mitchell, M. (1994). In-group identification, social dominance orientation, and differential intergroup social allocation. The Journal of Social Psychology, 134(2), 151-167.

Smirnov, O., Dawes, C. T., Fowler, J. H., Johnson, T., \& McElreath, R. (2010). The behavioral logic of collective action: partisans cooperate and punish more than nonpartisans. Political Psychology, 31(4), 595-616.

Smith, V. L. (1982). Microeconomic systems as an experimental science. The American Economic Review, 72(5), 923-955.

Smith, V. L. (1976). Experimental economics: induced value theory. The American Economic Review, 66(2), 274-279.

Stanley, S. K., Milfont, T. L., Wilson, M. S., \& Sibley, C. G. (2019). The influence of social dominance orientation and right-wing authoritarianism on environmentalism: a five-year cross-lagged analysis. PloS One, 14(7).

Tajfel, H., \& Turner, J. C. (1979). An Integrative Theory of Intergroup Conflict. In S. Worchel, \& W. G. Austin (Eds.), The Social Psychology of Intergroup Relations (pp. 33-47). Monterey, CA: Brooks/Cole.

Thielmann, I., Spadaro, G., \& Balliet, D. (2020). Personality and prosocial behavior: a theoretical framework and meta-analysis. Psychological Bulletin, 146(1), 30.

Thomsson, K. M., \& Vostroknutov, A. (2017). Small-world conservatives and rigid liberals: attitudes towards sharing in self-proclaimed left and right. Journal of Economic Behavior \& Organization, 135, 181-192.

Tomasello, M., Melis, A. P., Tennie, C., Wyman, E., Herrmann, E., Gilby, I. C., ... \& Melis, A. (2012). Two key steps in the evolution of human cooperation: the interdependence hypothesis. Current Anthropology, 53(6), 000-000.

Van Lange, P. A., Bekkers, R., Chirumbolo, A., \& Leone, L. (2012). Are conservatives less likely to be prosocial than liberals? From games to ideology, political preferences and voting. European Journal of Personality, 26(5), 461-473.

Vollan, B., Landmann, A., Zhou, Y., Hu, B., \& Herrmann-Pillath, C. (2017). Cooperation and authoritarian values: an experimental study in China. European Economic Review, 93, 90105.

Weng, H. Y., Fox, A. S., Hessenthaler, H. C., Stodola, D. E., \& Davidson, R. J. (2015). The role of compassion in altruistic helping and punishment behavior. PloS One, 10(12).

Yamagishi, T., Horita, Y., Mifune, N., Hashimoto, H., Li, Y., Shinada, M., ... \& Simunovic, D. (2012). Rejection of unfair offers in the ultimatum game is no evidence of strong reciprocity. Proceedings of the National Academy of Sciences, 109(50), 20364-20368.

Zhao, K., Ferguson, E., \& Smillie, L. D. (2017b). Politeness and compassion differentially predict adherence to fairness norms and interventions to norm violations in economic games. Scientific Reports, 7(1), 1-11. 